\title{
Evaluating the Importance of Apoptotic Index, Mitotic Index and Turnover Index in Premalignant and Malignant Lesions of Cervix
}

\author{
Subhash Bhardwaj1, Farooq Ahmed Wani ${ }^{2 *}$ \\ ${ }^{1}$ Department of Pathology, Government Medical College, Jammu, India \\ ${ }^{2}$ Department of Pathology, Aljouf College of Medicine, Sakaka, KSA \\ Email: drbhardwaj963@gmail.com, ${ }^{*}$ fawani@ju.edu.sa
}

Received 15 February 2015; accepted 24 March 2015; published 25 March 2015

Copyright (C) 2015 by authors and Scientific Research Publishing Inc.

This work is licensed under the Creative Commons Attribution International License (CC BY). http://creativecommons.org/licenses/by/4.0/

(c) (7) Open Access

\section{Abstract}

Aim: To evaluate the premalignant and malignant lesions of the uterine cervix on light microscopy for apoptosis. To calculate and correlate the apoptotic index (AI), mitotic index (MI) and turnover index of the lesions. Materials and methods: A 2-year retrospective (November 2007 to October 2009) and 1-year prospective study (November 2009 to October 2010). A total of 95 cases of premalignant and malignant lesions of cervix were studied. The hematoxylin-eosin stained slides were screened for apoptosis under oil immersion lens. Apoptotic index (AI) was calculated as the number of Apoptotic cells and Apoptotic bodies, expressed as percentage of total no. of tumour cells counted in each case. Mitotic index (MI) was calculated by counting mitosis among 1000 tumour cells. Turnover index (TOI) was obtained by adding MI and AI, i.e., (TOI = MI + AI). After calculating, all these indices were correlated with different grades of the cervical lesions. Results: Premalignant lesions were divided into four subgroups. On statistical analysis, it was found that the difference in the apoptotic indices and turnover indices in all the four subgroups was not statistically significant. However for mitotic indices, significant statistical difference was found in Subgroup II (mild dysplasia vs. moderate dysplasia) with a $p$ value of 0.03 and in subgroup IV (squamous metaplasia vs. moderate/severe dysplasia) with a $p$ value of 0.0005 . Within the malignant group, we compared well differentiated with less well differentiated subgroup. Statistical analysis revealed a significant difference in TOI between the two subgroups of malignant tumours $(p=0.04)$. Statistical comparison between premalignant and malignant group of lesions showed a highly significant difference between the AI, MI and TOI with p value of 0.0001 . Conclusion: We conclude that proliferative and apoptotic indices are useful in distinguishing between benign and malignant lesions of the cervix. Proliferative activity of a lesion is a reliable indicator of its malig-

${ }^{*}$ Corresponding author.

How to cite this paper: Bhardwaj, S. and Wani, F.A. (2015) Evaluating the Importance of Apoptotic Index, Mitotic Index and Turnover Index in Premalignant and Malignant Lesions of Cervix. Open Journal of Pathology, 5, 29-37. 
nant potential and together with apoptotic count gives an idea about the net growth of a tumour.

\title{
Keywords
}

\author{
Apoptosis, Apoptotic Index, Mitosis, Cervical Carcinoma
}

\section{Introduction}

Apoptosis or programmed cell death is the cell's intrinsic death program that regulates various physiological as well as pathological processes [1]. Kerr, at University of Queensland was first to distinguish apoptosis (Greek: apo-from, ptosis-falling) from traumatic cell death and credited James Cormack, a Professor of Greek language at University of Aberdeen, with suggesting the term apoptosis [2]. DNA or chromosomal lesions are detected by the p53 pathway which causes repair or induces apoptosis if the repair process is defective as in neoplasias. Thus, apoptosis plays a role in eliminating the cells with lesions in the genome thereby suppressing malignant transformation [3] [4]. Apoptosis also prevents the development of aneuploidy and other genetic abnormalities commonly associated with cancer cells and progression of neoplasia [5] [6].

The tendency of a cancer cell to undergo apoptosis may have important implications for tumour progression and response to treatment [7]. Tumours showing apoptosis are more sensitive to chemotherapy and likely to have a better prognosis thereby indicating the fact that the beneficial anti cancer effects of chemotherapy are predominantly mediated through induction of apoptosis in tumour cells [8]. However, some reports have suggested that the presence of active apoptosis in a variety of human cancers is associated with a poor outcome [9][12]. This may be due to the reason that hypoxia of the tumour cells within the growing neoplastic mass induces apoptosis [13] but at the same time causes selective accumulation of cells that can survive in a hypoxic environment. Thus, a paradoxical situation may happen whereby tumour demonstrates florid apoptosis, but at the same time progresses to a more malignant phenotype [14].

It is generally accepted that electron microscopy is the best way to identify apoptotic cells [15]. Apoptosis can also be demonstrated in tissues by in situ end labeling (ISEL) and TUNNEL method (TdT mediated dUTP-biotin nick end labeling) [16] [17]. Though these procedures are more sensitive but due to their cost consideration and lack of availability they are not practiced routinely. On the other hand, light microscopy which is based purely on morphology is fairly reliable, easily practiced and inexpensive method for detection of apoptosis.

There are many studies available in the literature that have evaluated the apoptosis by light microscopy in variety of human tumours, yet there are very few studies available from India, which have studied the apoptosis with light microscopy in premalignant and malignant lesions of uterine cervix. Cervical cancer is the third most common cancer affecting women worldwide, the most common cancer in women in India and several less developed countries [18]. We have chosen cervix for our study because of the above mentioned reasons. Moreover cervix is easily accessible site and requires less invasive technique for cervical biopsy.

\section{Risk Factors and Symptoms of Cervical Cancer}

Human Papillomavirus is considered to be the most important agent in cervical oncogenesis. Presence of cancer associated HPV and persistent detection of high risk HPV such as HPV 16, 18 are the most important risk factors associated with cervical cancer. Other risk factors are early age at first intercourse, multiple sexual partners, increased parity, a male partner with multiple sexual partners, exposure to oral contraceptives and nicotine; genital infections such as Chlamydia, immune status and low socioeconomic background [19].

The most common symptoms of cervical cancer are copious foul-smelling vaginal discharge, abnormal bleeding or inter-menstrual bleeding, post-coital bleeding, postmenopausal bleeding or backache [18].

\section{Materials and Methods}

The present study is a retrospective study for a period of 2 years from November, 2007 to October, 2009 and prospective study from November 2009 to October 2010. For the retrospective study all the slides available in the department of Pathology, Government Medical College, Jammu which were histologically diagnosed as 
premalignant or malignant lesions of uterine cervix on cervical biopsies were retrieved from the histopathology archives and screened. In cases where the slide material was not adequate or the quality of the slide was poor, the paraffin blocks were retrieved and fresh slides were prepared for the study. During this period of two years a total no. of 54 cases were reported.

The prospective study included a total no. of 41 cases of premalignant and malignant cervical lesions received in the department of Pathology, Government Medical College, Jammu from November, 2009 to October, 2010. All the chemicals used in this study were purchased by the Pathology department from the Ranbaxy India Limited and Merck Chemicals India. The cervical biopsy specimen were fixed in $10 \%$ buffered formalin, dehydrated in ascending grades of alcohol, cleared in xylene and finally embedded in paraffin. 2 - 5 micron thick paraffin sections of uniform thickness were cut on a rotary microtome, dewaxed and stained with hematoxylin and eosin. Hematoxylin and eosin staining was done as follows:

1) After dewaxing in xylene, sections were rehydrated to water by passing through descending grades of alcohol;

2) Stained with Harris Hematoxylin for 10 - 15 min;

3) Rinsed in tap water followed by differentiation in $1 \%$ acid alcohol;

4) Sections were washed in tap water until they become blue;

5) Stained with eosin for 2 - 3 min;

6) Dehydrated by passing through ascending grades of alcohol;

7) Cleared in xylene and mounted in DPX (dibutyl phthalate xylene).

A detailed histopathological examination of hematoxylin and eosin stained slides was carried out. Premalignant group of lesions included were squamous metaplasia, mild dysplasia, moderate dysplasia and severe dysplasia (Figure 1 and Figure 2). Malignant group of lesions included were well differentiated to less well differentiated keratinizing squamous cell carcinoma, non keratinizing squamous cell carcinoma, adenocarcinoma, adenosquamous and other subtypes.

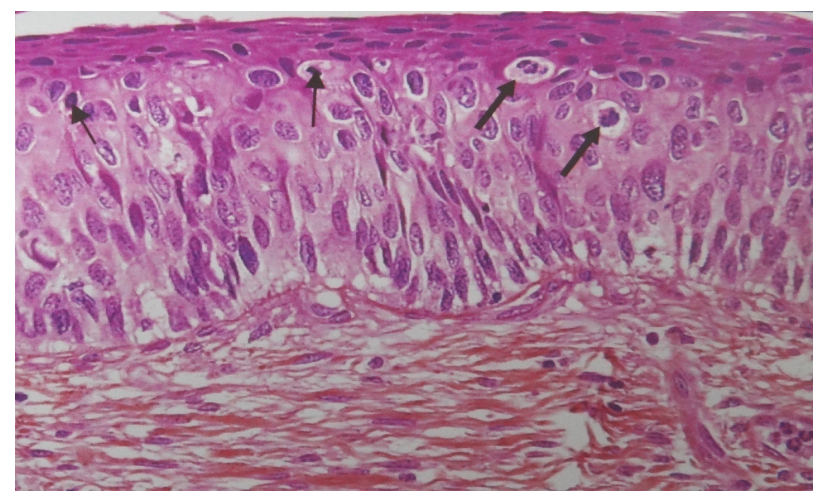

Figure 1. Photomicrograph from a case of severe dysplasia cervix showing many apoptotic cells (thin arrows) and abnormal mitotic figures (thick arrows) (H \& E 40× 10×).

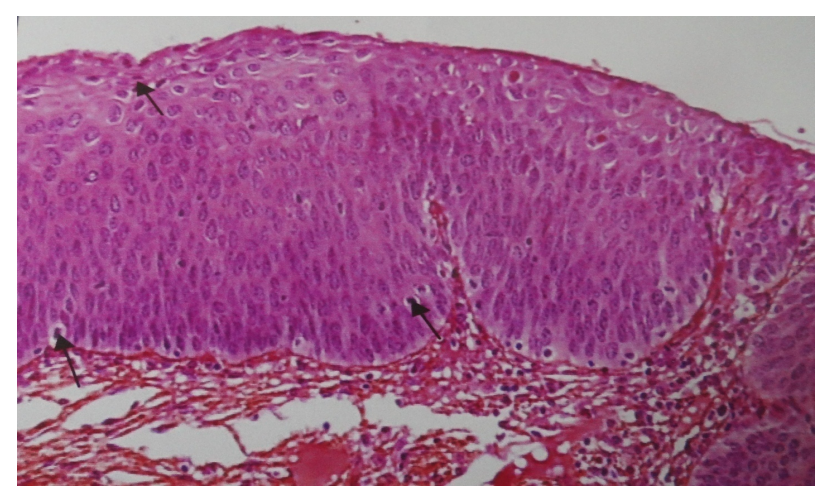

Figure 2. Photomicrograph from a case of moderate dysplasia cervix showing many apoptotic cells (arrows) (H \& E 20× 10×). 
The hematoxylin-eosin stained slides were screened under 40× objective and 10× eye piece, but the final count of apoptotic cells was carried out under high magnification (oil immersion $\times 100$ lens). From each section, 5 fields devoid of any preservation or fixation artifacts, inflammation and necrosis were selected. Apoptotic cells/bodies in the stroma around the tumours were not counted. In each section, 1000 tumour cells were evaluated for presence of apoptotic cells and Apoptotic bodies. Apoptotic cells with characteristic features of cell shrinkage, condensation and deep eosinophilia of cytoplasm and pyknotic, round to crescentric or irregular nucleus were identified. Apoptotic bodies which typically appear as tiny, round and pyknotic nuclear fragments are seen scattered amongst the tumour cells and occasionally forming small clusters were also identified. Apoptotic index (AI) was calculated as the number of Apoptotic cells and Apoptotic bodies, expressed as percentage of total no. of tumour cells counted in each case. Similarly, mitotic index (MI) was also calculated by counting mitosis among 1000 tumour cells or from dysplastic cells in CIN or from metaplastic lesions in cervical biopsy specimen. Turnover index (TOI) was obtained from sum of MI and AI, i.e., (TOI = MI + AI). After calculating the apoptotic index, mitotic index and turnover index, they were correlated with different grades of the cervical lesions.

\section{Statistical Analysis}

The data was analyzed with the help of CDC Epi-Info 7. Mean and standard deviation of apoptotic indices, mitotic indices and turnover indices were calculated for all the subgroups. Fischer's exact test and Mann Whitney test were used as tests of significance between the sub-groups. Student T-test was used for comparing all the three indices between premalignant and malignant group and also between subgroups of the malignant group.

\section{Results}

This study was conducted on 95 cases of various cervical lesions to evaluate apoptotic index (AI), Mitotic index (MI) and TOI (Turn over index) and to correlate these indices with different grades of cervical lesions.

In the present study, age wise analysis after grouping the lesions into premalignant and malignant types revealed that the maximum no. of premalignant lesions were in between the age group of 35 to 54 years (54.5\%) and malignant lesions were in the age group 45 - 64 years (69.3\%). Histologically, the most common type of premalignant lesion was squamous metaplasia (54.54\%) and the most common type of malignant lesion was keratinizing squamous cell carcinoma (69.35\%).

For statistical analysis, we divided the premalignant lesions into four subgroups: Subgroup I (Squamous metaplasia vs. mild dysplasia), Subgroup II (mild dysplasia vs. moderate dysplasia), Subgroup III (moderate dysplasia vs. severe dysplasia) and Subgroup IV (Squamous metaplasia vs. moderate/severe dysplasia).

The mean apoptotic indices of premalignant group of lesions, i.e., squamous metaplasia, mild dysplasia, moderate dysplasia and severe dysplasia were $0.71 \pm 0.3$, $0.62 \pm 0.6,1 \pm 0.44$ and $1 \pm 0.6$ respectively (Table 1 ). On statistical analysis, it was found that the difference in the apoptotic indices amongst all the four subgroups was not statistically significant (Table 2).

For mitotic index, the mean value for squamous metaplasia, mild dysplasia, moderate dysplasia and severe dysplasia were $0.005 \pm 0.02,0.009 \pm 0.08,0.15 \pm 0.05$ and $0.25 \pm 0.05$ respectively (Table 1 ). On statistical analysis, significant statistical difference was found in Subgroup II (mild dysplasia vs. moderate dysplasia) with a p value of 0.03 and in Subgroup IV (squamous metaplasia vs. moderate/severe dysplasia) with a p value of 0.0005 (Table 2).

The turnover indices of squamous metaplasia, mild dysplasia, moderate dysplasia and severe dysplasia were $0.72 \pm 0.42,0.63 \pm 0.6,1 \pm 0.44$ and $1.25 \pm 0.54$ respectively (Table 1 ). No statistically significant difference was found among all the four subgroups (Table 2).

The mean apoptotic indices of malignant group of tumours, i.e., keratinizing squamous cell carcinoma, nonkeratinizing squamous cell carcinoma, adenocarcinoma and adenosquamous carcinoma were $3.38 \pm 1.15$, $2.92 \pm$ $1.41,1.76 \pm 1.2$ and $3.65 \pm 0.72$ respectively; the mean mitotic indices were $0.57 \pm 0.55,0.42 \pm 0.26,0.2 \pm 0.07$ and $0.2 \pm 0.04$ respectively and the mean turnover indices were $3.96 \pm 1.38,3.27 \pm 1.5,1.96 \pm 0.9$ and $3.85 \pm$ 0.42 respectively (Table 1 ).

Within the malignant group, we compared well differentiated (keratinizing squamous cell carcinoma) with less well differentiated groups (non-keratinizing squamous cell carcinoma, adenocarcinoma and adenosquamous carcinoma). Statistical analysis revealed a significant difference in TOI between the two subgroups of malignant tumours (Table 3). 
Table 1. Apoptotic indices, mitotic indices and turnover indices in the various cervical epithelial lesions.

\begin{tabular}{ccccc}
\hline Diagnosis & No. of cases & $\begin{array}{c}\text { Apoptotic index } \\
\text { (mean } \pm \text { SD) }\end{array}$ & $\begin{array}{c}\text { Mitotic index } \\
\text { (mean } \pm \text { SD) }\end{array}$ & $\begin{array}{c}\text { Turnover index } \\
\text { (mean } \pm \text { SD) }\end{array}$ \\
\hline $\begin{array}{c}\text { Squamous metaplasia } \\
\text { Mild dysplasia }\end{array}$ & 18 & $0.71 \pm 0.3$ & $0.005 \pm 0.02$ & $0.72 \pm 0.42$ \\
$\begin{array}{c}\text { Moderate dysplasia } \\
\text { Severe dysplasia }\end{array}$ & 11 & $0.62 \pm 0.6$ & $0.009 \pm 0.08$ & $0.63 \pm 0.6$ \\
$\begin{array}{c}\text { Keratinizing squamous cell } \\
\text { carcinoma }\end{array}$ & 2 & $1 \pm 0.44$ & $0.15 \pm 0.05$ & $1 \pm 0.44$ \\
$\begin{array}{c}\text { Non-keratinizing squamous cell } \\
\text { carcinoma }\end{array}$ & 14 & $1 \pm 0.06$ & $0.25 \pm 0.05$ & $1.25 \pm 0.54$ \\
$\begin{array}{c}\text { Adenocarcinoma } \\
\text { Adenosquamous carcinoma }\end{array}$ & 3 & $3.38 \pm 1.15$ & $0.57 \pm 0.55$ & $3.96 \pm 1.38$ \\
\hline
\end{tabular}

Table 2. Mean apoptotic indices, mitotic indices, turnover indices and statistical inference (Student’s T-test) in different subgroups of premalignant group.

\begin{tabular}{ccccc}
\hline & $\begin{array}{c}\text { Squamous metaplasia vs. } \\
\text { Mild dysplasia }\end{array}$ & $\begin{array}{c}\text { Mild dysplasia vs. } \\
\text { Moderate dysplasia }\end{array}$ & $\begin{array}{c}\text { Moderate dysplasia vs. } \\
\text { Severe dysplasia }\end{array}$ & $\begin{array}{c}\text { Squamous metaplasia vs. } \\
\text { Mod/Severe dysplasia }\end{array}$ \\
\hline Apoptotic index & 0.669 & 0.447 & $0.102^{\dagger+}$ & 0.973 \\
Mitotic index & $1^{\dagger}$ & $0.03^{*+}$ & $0.102^{\dagger+}$ & $0.0005^{* \dagger}$ \\
Turnover index & 0.69 & 0.473 & $1^{\dagger+}$ & 0.519 \\
\hline
\end{tabular}

${ }^{\dagger}$ Fisher's exact test; ${ }^{\dagger \dagger}$ Mann Whitney test; ${ }^{*}$ Significant.

Table 3. Mean apoptotic indices, mitotic indices, turnover indices and statistical inference (Student's T-test) between premalignant and malignant groups and between well differentiated and less differentiated subgoups.

\begin{tabular}{ccc}
\hline & Premalignant vs. Malignant & Well differentiated vs. Less differentiated \\
\hline Apoptotic index & $0.0001^{*}$ & 0.111 \\
Mitotic index & $0.0001^{*}$ & 0.128 \\
Turnover index & $0.0001^{*}$ & $0.04^{*}$ \\
\hline
\end{tabular}

${ }^{* *}$ Highly significant; ${ }^{*}$ Significant.

Statistical comparison between premalignant and malignant group of lesions showed a highly significant difference between the AI, MI and TOI of premalignant group of lesions and malignant group of lesions with a p value of $\mathrm{p}=0.0001$ (Table 3 ).

\section{Discussion}

Cervix is commonly affected with various pathological conditions like cervicitis, hyperplasia, metaplasia, dysplasia, benign tumours and malignant neoplasms. Squamous cell carcinomas irrespective of the site, evolves through a sequence of changes occurring in the normal squamous epithelium, ranging from dysplasia of varying degrees to frank malignancy [20]. Cervical cancer is the third most common cancer among women worldwide, with an estimated 529,000 new cases and 275,000 deaths in 2008. More than 85\% of the global burden of cervical cancer cases and 88\% of cervical cancer deaths occur in developing countries. Cervical cancer is the most common cancer among Indian women causing 134,420 new cases and 72,825 deaths in the year 2008 [18] [21].

Biological behavior of the tumour depends not only on its proliferative activity but also on the number of cells dying either by apoptosis or by ischemic necrosis. Proliferative activity of a tumour depends on stimulatory growth signals from various oncogenes and may be accompanied by inactivation of one or more tumour suppressor genes [22]. Cell proliferation is an important feature of dysplasia and carcinoma. Several indices are used to measure cell proliferation such as mitotic index, PCNA, Ki-67 and AgNOR count; these have been recognized 
as useful prognostic indicators of tumour [23]. Apoptosis is recognized as a physiological mechanism for controlling cell numbers and its subversion is thought to contribute to carcinogenesis. Apoptotic cells are well recognized morphologically on light microscopy in formalin fixed H \& E stained slides. Various other methods to detect apoptosis are electron microscopy, flow cytometry, electrophoresis, in-situ nick translation and TUNEL method (Tdt mediated dUTP biotin nick labeling) [17].

Although apoptosis has been evaluated \& shown to correlate with tumor grade and subtype in some malignant lesions including those of large intestine, endometrium, prostate, breast [9] [24]-[26], yet there are very few studies available in literature from India, which have evaluated apoptosis using light microscopy in premalignant \& malignant lesions of uterine cervix. The present study is based purely on morphology as it is fairly reliable, easily practiced and inexpensive method for detection of both apoptosis and mitosis.

The present study was conducted on 95 cases of various cervical lesions to evaluate apoptotic index (AI), Mitotic index (MI) and TOI (Turn over index) and to correlate these indices with different grades of cervical lesions. In our study, maximum no. of premalignant lesions was in the age group of 35 to 54 years (54.5\%) and malignant lesions were in the age group 45 - 64 years (69.3\%). Vijaya et al. 2008 reported maximum no. of premalignant lesions between 35 - 54 years (61.1\%) and malignant lesions were in age group 35 - 64 years (80.2\%).

In the present study, majority of the lesions were malignant 62 cases (65.2\%) and 33 cases (34.73\%) were premalignant. Sagol, O., et al., 1999 conducted study on 55 (64.7\%) premalignant and 30 (35.2\%) malignant lesions (squamous cell carcinoma of cervix) [27]. Dey, P., et al., 2000 conducted study on 31 cases (68.8\%) of premalignant and 14 cases (31.1\%) of malignant lesions of uterine cervix. Vijaya, et al. 2008 have reported 124 cases $(62 \%)$ in premalignant and 76 cases $(38.0 \%)$ in malignant group.

Histologically, the most common type of premalignant lesion was squamous metaplasia (54.54\%) which is similar to results obtained by Vijaya, et al., 2008 who reported the most common type of premalignant lesions as squamous metaplasia (66.9\%). The most common type of malignant lesion in our study was keratinizing squamous cell carcinoma (69.35\%) followed by non-keratinizing squamous cell carcinoma (22.58\%).

In our study, comparison between the mean AI and mean TOI in Group I (squamous metaplasia vs. mild dysplasia) showed statistically insignificant difference (Table 2). Mean MI shows increase with increased grade of lesion from squamous metaplasia to mild dysplasia (Table 2) but when the results were analyzed statistically, it was found to be insignificant. Our study concluded that there is no much difference in apoptosis and mitosis between squamous metaplasia and mild dysplasia. However, Vijaya, et al., in their study reported mean AI and MI increases from squamous metaplasia to mild dysplasia and found statistically significant difference ( $\mathrm{p}<$ 0.01).

Present study shows that mean AI, MI and TOI in Group II (mild dysplasia vs. moderate dysplasia) and Group III (moderate dysplasia vs. severe dysplasia) increases with increasing rate, i.e., from mild dysplasia to moderate dysplasia to severe dysplasia. On statistical analysis mean AI and TOI is found to be statistically insignificant. This insignificant difference could be attributed to the lack in the number of cases in moderate and severe dysplasia, as our study involves both retrospective and prospective analysis and maximum number of patients reported with carcinoma cervix. Mean MI in Group II (mild dysplasia vs. moderate dysplasia) was found to be statistically significant $(p=0.03)$ (Table 2). Dey, P., et al. (2000) reported statistically insignificant difference in mean AI and MI in Group II and Group III and TOI of Group III. The statistically significant difference was found in mean TOI in Group II ( $p=0.044)$.

Vijaya, et al. (2008) reported that mean AI, MI increases with the severity of dysplasia in premalignant lesion. The difference was statistically significant $(\mathrm{p}<0.01$ ) in Group II (mild vs. moderate dysplasia) and Group III (moderate vs. severe dysplasia). Sagol, O., et al. (1999) did not find any statistically significant difference between CIN I and CIN II as well as between CIN II and CIN III groups in terms of apoptotic and mitotic cell counts. Mitotic cell counts were found statistically higher in CIN III group when compared with CIN I and CIN II groups together coinciding with the results of our study in Group II (mild vs. moderate dysplasia) and Group III (moderate vs. severe dysplasia). Pahuja, S., et al. (2003) reported cell proliferation by AgNOR count in various grades of pre-invasive cervical epithelial lesion and showed progressive rise in their mean value with increasing grade of pre-invasive lesion [28].

In the present study, we have done the additional statistical analysis for Group IV (Squamous metaplasia vs. moderate/severe dysplasias) and found that mean AI and TOI was statistically insignificant but mean MI is shown to be significant statistically $(\mathrm{p}=0.0005)$. This shows that number of mitosis increases with increasing 
grade of lesion.

We have also compared the mean AI, MI and TOI of malignant lesion as a whole group with the premalignant lesion and found that the AI, MI and TOI increased as the nature of lesion changed from premalignant to malignant. This difference between both the groups was very highly significant $(p=0.0001)$ (Table 3), this finding of our study suggests how the histological behavior of the lesions suddenly changes as they cross the thin red line between the premalignant and the malignant types. This also re-established the fact that these highly proliferating lesions also have high rate of cell turnover. Besides this, proliferative and apoptotic indices have also been found to be useful to distinguish between benign and malignant lesions of the cervix.

Vijaya et al. (2008) also reported significant difference $(\mathrm{p}<0.01)$ in mean AI and MI with increasing rates of lesion from dysplasia to carcinoma cervix. Dey, P., et al. (2000) reported that mean AI $(\mathrm{p}=0.0028)$, MI $(\mathrm{p}=$ $0.0018)$ and TOI $(p=0.0014)$ increases from lower to higher grades of CIN to carcinoma of cervix. The difference was found to be highly significant correlating our results with their study. Sagol, et al. (1999) also reported that the squamous cell carcinoma cervix group showed significantly higher mitotic and apoptotic cell counts when compared with pre-neoplastic lesions. They concluded that both apoptosis and mitosis are markedly increased in progression towards malignancy in cervical epithelium. Mitotic cell counts may be helpful in predicting the extent of the disease in squamous cell carcinoma cervix

In the present study, we further subdivided the malignant lesions into well differentiated (KSCC) and less well differentiated (NKSCC, adenocarcinoma, adenosquamous carcinoma lesions) and compared the AI, MI and TOI. There was no statistically significant difference between the AI and MI of both the groups. The difference in TOI was however statistically significant $(p=0.04)$ (Table 3$)$. Since the majority of malignant lesions were in well differentiated group (43 cases i.e., 69.35\%), the relationship between the various indices could not be accurately determined and this is attributed to the statistically insignificant difference in AI and MI.

Our results correlate with Sagol, O., et al. (1999) who also reported that there was no statistically significant difference in the apoptotic and mitotic cell counts between non-keratinizing and keratinizing squamous cell carcinoma. They also showed that in the squamous cell carcinoma group, apoptotic cell counts did not show significant difference between tumour stages but mitotic counts were significantly higher in advanced stage tumours.

To conclude, the apoptotic cells can be easily demonstrated in routine H \& E stained sections, though a high degree of variability still exist in the apoptotic index reported by various authors. To avoid this inter-observer variability the established criteria for recognition and counting of apoptotic cells should be strictly adhered so that the cervical lesions can be characterized properly according to their potential for invasiveness.

\section{Conclusions}

We conclude that apoptotic cells and mitosis can be readily and accurately demonstrated on routine $\mathrm{H}$ \& $\mathrm{E}$ stained sections. AI and MI are the simplest techniques that can be employed in any laboratory. Proliferative and apoptotic indices have been found useful in distinguishing between benign and malignant lesions of the cervix. Observed increase in apoptotic cell with the grade of the lesion suggests a mechanism whereby apoptosis helps to eliminate cells that have been produced in excess.

We also conclude that proliferative activity of a lesion is a reliable indicator of its malignant potential and together with apoptotic count gives an idea about the net growth of a tumour.

\section{Conflict of Interest}

Nil.

\section{References}

[1] Lockshin, R.A. and Zakeri, Z. (2007) Cell Death in Health and Disease. Journal of Cellular and Molecular Medicine, 11, 1214-1224. http://dx.doi.org/10.1111/j.1582-4934.2007.00150.x

[2] Kerr, J.F., Wyllie, A.H. and Currie, A.R. (1972) Apoptosis: A Basic Biological Phenomenon with Wide-Ranging Implications in Tissue Kinetics. British Journal of Cancer, 26, 239-257. http://dx.doi.org/10.1038/bjc.1972.33

[3] Lane, D.P. (1992) p53, Guardian of the Genome. Nature, 358, 15-16. http://dx.doi.org/10.1038/358015a0

[4] Vogelstein, B. and Kinzler, K.W. (1992) p53 Function and Dysfunction. Cell, 70, 523-526. 
http://dx.doi.org/10.1016/0092-8674(92)90421-8

[5] Schimke, R.T., Kung, A., Sherwood, S.S., Sheridan, J. and Sharma, R. (1995) Life, Death and Genomic Change in Perturbed Cell Cycles. In: Dexter, T.M., Raff, M.C. and Wyllie, A.H., Eds., The Role of Apoptosis in Development, Tissue Homeostasis and Malignancy, Chapman and Hall, London, 75-81. http://dx.doi.org/10.1007/978-94-011-0553-8 13

[6] Symonds, H., Krall, L., Remington, L., Saenz-Rubles, M., Lowe, S., Jacks, T. and Van, D.T. (1994) P53-Dependent Apoptosis Suppresses Tumour Growth and Progression in Vivo. Cell, 78, 703-711. http://dx.doi.org/10.1016/0092-8674(94)90534-7

[7] Kerr, J.F.R., Winterford, C.M. and Harman, B.V. (1994) Apoptosis: Its Significance in Cancer and Cancer Therapy. Cancer, 73, 2013-2026. http://dx.doi.org/10.1002/1097-0142(19940415)73:8<2013::AID-CNCR2820730802>3.0.CO;2-J

[8] Darzynkiewicz, Z. (1995) Apoptosis in Anti Tumour Strategies: Modulation of Cell Cycle or Differentiation. Journal of Cellular Biochemistry, 58, 151-159. http://dx.doi.org/10.1002/jcb.240580204

[9] Lipponen, P., Aaltomaa, S., Kosma, V.M. and Syrjänen, K. (1994) Apoptosis in Breast Cancer as Related to Histopathological Characteristics and Prognosis. European Journal of Cancer, 30A, 2068-2073. http://dx.doi.org/10.1016/0959-8049(94)00342-3

[10] Lipponen, P.K. and Aaltomaa, S. (1994) Apoptosis in Bladder Cancer as Related to Standard Prognostic Factors and Prognosis. The Journal of Pathology, 173, 333-339. http://dx.doi.org/10.1002/path.1711730408

[11] Stapleton, A.M.F., Zhell, P., Kattan, M.W., Yang, G., Wheeler, T.M., Schardino, P.T. and Thompson, T.C. (1998) Assessment of the Biologic Markers p53, Ki-67, and Apoptotic Index as Predictive Indicators of Prostatic Carcinoma Recurrence after Surgery. Cancer, 82, 168-173. http://dx.doi.org/10.1002/(SICI)1097-0142(19980101)82:1<168::AID-CNCR21>3.0.CO;2-\#

[12] Törmanen, U., Eerola, A.K., Rainio, P., Vahakanagas, K., Soini, Y., Sormunen, R., Bloigu, R., Lehto, V.P. and Paakkö, P. (1995) Enhanced Apoptosis Predicts Shortened Survival in Non-Small Cell Lung Carcinoma. Cancer Research, 55, 5595.

[13] Yao, K.S., Clayton, M. and O’Dwyer, P.J. (1995) Apoptosis in Human Adeocarcinoma HT29 Cells Induced by Exposure to Hypoxia. Journal of the National Cancer Institute, 87, 117-122. http://dx.doi.org/10.1093/jnci/87.2.117

[14] Kinzlar, K.W. and Vogelstein, B. (1996) Life (and Death) in a Malignant Tumour. Nature, 379, $19-20$. http://dx.doi.org/10.1038/379019a0

[15] Harrison, D.J. (1996) Counting Apoptosis-Why and How? Journal of Clinical Pathology-Molecular Pathology, 49, 245-246. http://dx.doi.org/10.1136/mp.49.5.M245

[16] Ansari, B., Coates, P.J., Greenstein, B.D. and Hall, P.A. (1993) In Situ End-Labelling Detects DNA Strand Breaks in Apoptosis and Other Physiological and Pathological States. The Journal of Pathology, 170, 1-8. http://dx.doi.org/10.1002/path.1711700102

[17] Gavrieli, Y., Sherman, Y. and Ben-Sasson, S.A. (1992) Identification of Programmed Cell Death in Situ via Specific Labeling of Nuclear DNA Fragmentation. Journal of Cell Biology, 119, 493-501. http://dx.doi.org/10.1083/jcb.119.3.493

[18] Mishra, G.A., Pimple, S.A. and Shastri, S.S. (2011) An Overview of Prevention and Early Detection of Cervical Cancers. Indian Journal of Medical and Paediatric Oncology, 32, 125-132.

[19] Crum, C.P. (2004) The Female Genital Tract. In: Kumar, V., Abbas, A.K. and Fausto, N., Eds., Robbins and Cotran, Pathologic Basis of Disease, 7th Edition, WB Saunders Company Elsevier Inc., Philadelphia, 1072-1079.

[20] Mysorekar, V.V., David, S. and Rao, S.G. (2008) Proliferative and Apoptotic Indices in Squamous Epithelial Lesions of the Cervix. Bahrain Medical Bulletin, 30, 156-159.

[21] Ferlay, J., Shin, H.R., Bray, F., Forman, D., Mathers, C. and Parkin, D.M. (2010) Estimates of Worldwide Burden of Cancer in 2008: GLOBOCAN 2008. International Journal of Cancer, 127, 2893-2917. http://dx.doi.org/10.1002/ijc.25516

[22] Dey, P., Das, R. and Sabuddin (2000) Correlations between Apoptotic and Proliferative Indices in Cervical Intraepithelial Neoplasia and Carcinoma. Indian Journal of Pathology \& Microbiology, 43, 271-275.

[23] Hall, P.A., Levison, D.A., Woods, A.L., Yu, C.C., Kellock, D.B., Watkins, J.A., Barnes, D.M., Gillett, C.E., Camplejohn, R., Dover, R., et al. (1990) Proliferating Cell Nuclear Antigen (PCNA) Immunolocalization in Paraffin Sections: An Index of Cell Proliferation with Evidence of Deregulated Expression in Some Neoplasms. The Journal of Pathology, 162, 285-294. http://dx.doi.org/10.1002/path.1711620403

[24] Sugamura, K., Makino, M. and Kaibara, N. (1998) Apoptosis as a Prognostic Factor in Colorectal Carcinoma. Surgery Today (Tokyo), 28, 145-150. http://dx.doi.org/10.1007/s005950050096 
[25] Heatley, M.K. (1995) Association between the Apoptotic Index and Established Prognostic Parameters in Endometrial Adenocarcinoma. Histopathology (Oxford), 27, 469-472. http://dx.doi.org/10.1111/j.1365-2559.1995.tb00312.x

[26] Aihara, M., Truong, L.D., Dunn, J.K., Wheeler, T.M., Scardino, P.T. and Thompson, T.C. (1994) Frequency of Apoptotic Bodies Positively Correlates with Gleason Grade in Prostate Cancer. Human Pathology, 25, 797-801. http://dx.doi.org/10.1016/0046-8177(94)90249-6

[27] Sagol, O., Yorukoglu, K., Sagol, S., Koyuncuoglu, M. and Uslu, T. (1999) Apoptotic and Mitotic Index in Squamous Cell Carcinomas and Premalignant Lesions of the Uterine Cervix. International Journal of Surgical Pathology, 7, 155160. http://dx.doi.org/10.1177/106689699900700305

[28] Pahuja, S., Choudhury, M. and Gupta, U. (2003) Proliferative Activity in Squamous Intraepithelial and Invasive Lesions of Cervix: Analysis by AgNOR Staining. Indian Journal of Pathology \& Microbiology, 46, 573-575.

\section{Abbreviations Used}

$\mathrm{AI}=$ Apoptotic Index;

$\mathrm{MI}=$ Mitotic Index (MI);

TOI = Turnover Index;

HPV = Human Papillomavirus;

$\mathrm{H} \& \mathrm{E}=$ Hematoxylin and Eosin;

CIN = Cervical Intraepithelial Neoplasia;

ISEL = In Situ End Labeling;

TUNNEL = TdT Mediated dUTP-Biotin Nick End Labeling;

KSCC $=$ Keratinizing Squamous Cell Carcinoma;

NKSCC $=$ Non-Keratinizing Squamous Cell Carcinoma. 